\title{
Study of free vibration analysis of laminated composite plates with triangular cutouts
}

\author{
Harsh Kumar Bhardwaj*, Jyoti Vimal and Avadesh Kumar Sharma
}

Department of Mechanical Engineering, Madhav Institute of Technology and Science, Gwalior, India

\begin{tabular}{|c|c|}
\hline ARTICLE INFO & A B S T RACT \\
\hline $\begin{array}{l}\text { Article history: } \\
\text { Received March 6, } 2014 \\
\text { Accepted 28 November } 2014 \\
\text { Available online } \\
\text { 28 November } 2014 \\
\text { Keywords: } \\
\text { Free Vibration } \\
\text { FEM } \\
\text { Composite plate } \\
\text { Triangular cut-out }\end{array}$ & $\begin{array}{l}\text { Cutouts are commonly used as access port for mechanical and electrical structures. Most of the } \\
\text { structures generally work under severe dynamic loading and different constrained conditions } \\
\text { during their service life. This may lead to vibration of the structure. Therefore, it is necessary to } \\
\text { predict the vibration responses of laminated composite plates with cutouts precisely with less } \\
\text { computational cost and good accuracy of these complex structures. A suitable finite element } \\
\text { model is proposed and developed based on first order shear deformation theory using ANSYS } \\
\text { parametric design language (APDL) code. The model has been discretized using an appropriate } \\
\text { eight nodded element (SHELL 281) from the ANSYS element library. The free vibrations are } \\
\text { computed using Block-Lanczos algorithm. The convergence study has been done of the } \\
\text { developed model and compared with those available published literature. Effects of different } \\
\text { geometric parameters (aspect ratio, thickness ratio, boundary conditions, number of layers, } \\
\text { angle of lamina geometry of cutout, cutout side to plate side ratio and distance between cutouts) } \\
\text { and material properties on the free vibration responses are discussed in detail. The frequency } \\
\text { increases with increase in the number of layers, modulus ratio of plate and angle of lamina. The } \\
\text { frequency decreases with increase in aspect ratio, thickness ratio, size of cutout and distance } \\
\text { between cutouts. The boundary conditions of the plate play an important role in the free } \\
\text { vibrations of the plate with cutouts. The Non-dimensional frequencies are higher for fully } \\
\text { clamped boundary condition in comparison to other boundary conditions. }\end{array}$ \\
\hline
\end{tabular}

\section{Introduction}

Composite laminates are assemblies of layers of fibrous composite materials which can be joined to provide required engineering properties, including in-plane stiffness, bending stiffness, strength and coefficient of thermal expansion. Laminated composite structures are increasingly being used in many engineering fields such as aerospace, marine vehicles, automotive, chemical and nuclear engineering. Cutouts are essential for assembling the components, access ports, damage inspection, fuel lines and electrical lines, opening in a structure to serve as doors and windows, provide ventilation, to reduce weight and for accessibility to other parts of the structure. It is required at the

* Corresponding author.

E-mail addresses: harsh.bhardwaj80@gmail.com (H. K. Bhardwaj) 
bottom plate for some passage of liquid in liquid retaining structures. It is also well recognized that these structures are exposed to the undesirable vibration and many more during their service life and again these plate structures having cutout may change the responses considerably. The plates with the cutouts reduces the total weight, which in turn influence on the vibration response. Hence, there is a need to study the vibration behavior of laminated composite structure with cutouts precisely.

The vibration responses of laminated composite plates have been extensively studied by a number of researchers. Some of the selected studies are discussed in the following lines. Civalek (2008) proposed the discrete singular convolution (DSC) technique for free vibration analysis of moderately thick symmetrically laminated composite plates based on the first order shear deformation theory. The results were also compared with those obtained by the other numerical and analytical method. Ngo-Cong et al. (2011) presented radial basis function (RBF) collocation technique for the free vibration analysis of laminated composite plates applying the first order shear deformation theory (FSDT). Several examples concerning various thicknesses to material properties, span ratios and boundary conditions were considered. Cui et al. (2011) investigated the bending and vibration analysis of laminated composite plate using a novel triangular composite plate element based on an edge based smoothing technique. Xiang et al. (2011) investigated the free vibration properties of laminated composite shells using the first order shear deformation theory and a meshless global collocation technique based on thin plate spline radial basis function. Grover et al. (2013) extended the inverse hyperbolic shear deformation theory to investigate the free vibration response of laminated composite and sandwich plates. Boscolo and Banerjee (2014) developed dynamic stiffness technique by using a sophisticated layer-wise theory which complies with the $C_{z}^{0}$ requirements and delivered high accuracy for the analysis of laminated composite plates. Marjanovic and Vuksanovic (2014) extended the layer wise plate theory of Reddy for the analysis of delamination as a basis for development of enriched finite elements. Effects of plate geometry, lamination scheme, degree of orthotropy and delamination size or position on dynamic characteristics of the plate are presented.

Aydogdu and Timarchi (2003) investigated the vibration analysis of cross-ply laminated square plates based on PSDPT with general boundary conditions. Sharma and Mittal (2010, 2011, 2013, 2014) studied the free vibration analysis of laminated composite plates with elastically restrained edges by applying FEM. Karami et al. (2006) developed the free vibration analysis of moderately thick symmetric laminated plates using elastically restrained edges. Liew et al (2003) investigated the free vibration analysis of symmetrically laminated plates based on FSDT using the moving least squares differential quadrature technique. Free vibration analysis of laminated composite rectangular plate was presented in the work of Pandit et al. (2007) by applying FEM. Numerical instances of isotropic and composite rectangular composite plates having various fiber orientation angle, thickness ratio and aspect ratio were also solved. Brethee (2009) studied the free vibration analysis of a symmetric and anti-symmetric laminated composite plate with a cut-out at the center. Lahouel and Guenfoud (2013) investigated the comparative analysis of vibration between laminated composite plates with and without holes under compressive loads. Luccioni and Dong (1998) presented Levitype (semi-analytical) finite element analysis of free vibration and stability of laminated composite rectangular plates based on both classical and first order shear deformation theories. Xiang et al. (2010) presented a meshless method based on thin plate spline radial basis functions and higher order shear deformation theory to study the free vibration of clamped laminated composite plates. Chen and Lue (2005) studied the free vibration analysis of cross-ply laminated plates with one pair of opposite edges simply supported. Suresh Kumar et al. (2011) developed an analytical procedure to investigate the free vibration characteristics of various laminated composite plates based on higher order shear displacement model with zig-zag function. In aerospace structures, panels with triangular cutouts are often used. Therefor it is important to study the vibration behavior of laminated composite structure with triangular cutout precisely. In this paper the effects of different geometric parameters (aspect ratio, thickness ratio, boundary conditions, number of layers, angle of lamina, geometry of cutout, 
cutout side to plate side ratio and distance between cutouts) and material properties on the free vibration responses are discussed in detail. It is shown that the frequency increases with increase in the number of layers, modulus ratio of plate and cutout size.

\section{Material and Methods}

The finite element software (ANSYS) is implemented with the aim of analyzing. In addition SHELL 281 is suitable for analyzing thin to moderately-thick shell structures. As demonstrated in Fig. 1, the element contains eight nodes with six degree of freedom at each node. SHELL 281 is wellsuited for linear, large rotation and/or large strain non-linear applications. SHEEL 281 may be used for layered applications for modeling composite shells or sandwich construction.

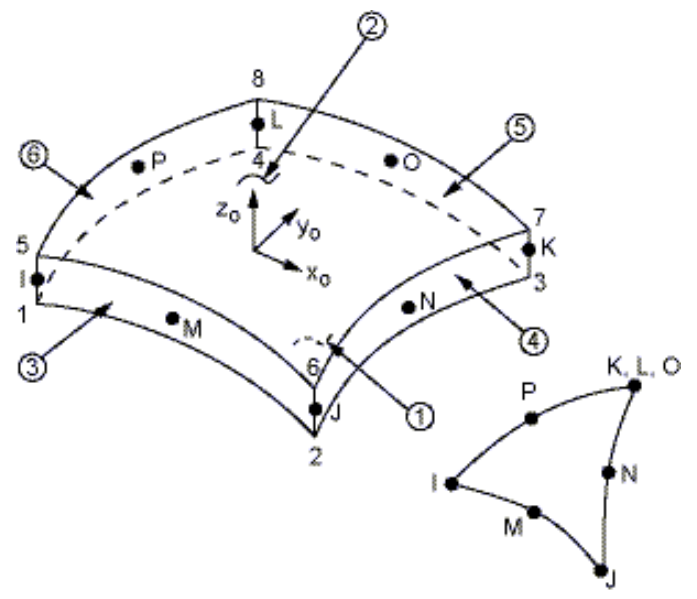

Fig. 1. SHELL 281 element

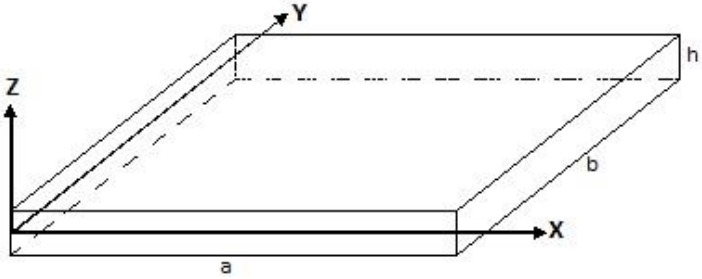

Fig. 2. Geometry of the composite laminated plate

It is mentioned that for free vibration analysis, subspace method is applied. The subspace iteration method was described in detail by Bathe (1996). Enhancements as suggested by Wilson and Itoh (1983) were also included as outlined subsequently.

\section{Numerical results and discussion}

Different cases of cross-ply composite laminates with triangular cut-out are examined here. Without loss of generality equal number of grid points in $\mathrm{x}$ - and $\mathrm{y}$ - direction is assumed. To define the boundary conditions along the edges the alphabet symbolism will be used, so that S-C-S-C indicates a plate with edge $\mathrm{x}=0$ simply supported, edge $\mathrm{y}=0$ clamped, edge $\mathrm{x}=\mathrm{a}$ simply supported and edge $\mathrm{y}=\mathrm{b}$ clamped, in which the $\mathrm{x}, \mathrm{y}$ and $\mathrm{z}$ axes have been shown in Fig. 2 for the investigated laminate.

\subsection{Convergence study}

\section{Cross-ply laminated plate}

To show the computational efficiency of FEM, a thin square plate composed with three orthotropic layers $\left(0^{0} / 90^{0} / 0^{0}\right)$ is considered. The material properties of each layer are

$$
\frac{E_{11}}{E_{22}}=25, \quad G_{12}=G_{13}=0.5 E_{22,}, G_{23}=0.2 E_{22}, v_{12}=0.25, \quad \rho=2700 \mathrm{~kg} / \mathrm{m}^{3}
$$

The accuracy and convergence behaviors of the solutions for a square laminate plate with two orthotropic layers $\left(0^{\circ} / 90^{\circ}\right)$ with cut-out at the center (shown in Fig. 3) were investigated, the results of which are shown in Table 1. To compare the solutions the results of Pandit et al. (2007) and 
Brethee (2009) are also cited. A good agreement of results is obtained between the present results and the results given by Pandit et al. (2007) and Brethee (2009).

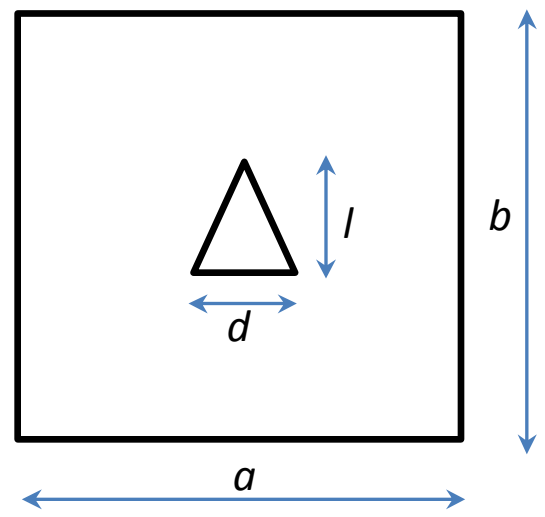

Fig. 3. Square plates with triangular cutout

\section{Angle-ply laminated plate}

The material properties of each layer for an angle-ply $\left(\theta^{0} /-\theta^{0} / \theta^{0}\right)$ square laminated plate are

$$
\frac{E_{11}}{E_{22}}=40, \quad G_{12}=G_{13}=0.6 E_{22}, G_{23}=0.5 E_{22}, v_{12}=0.25, \quad \rho=2700 \mathrm{~kg} / \mathrm{m}^{3}
$$

Table 1. Convergence study of non-dimensional frequencies $\left(\bar{\omega}=\frac{\omega a^{2}}{h} \sqrt{\frac{\rho}{E_{22}}}\right)$ for a cross-ply laminate $\left(0^{0} / 90^{\circ}\right)$ having a square cutout at the centre, $\left(K_{s}\right.$ (shear correction coefficient $)=5 / 6, \mathrm{~b} / \mathrm{a}=1$, $\mathrm{h} / \mathrm{a}=0.01$ ) for boundary condition i.e. CCCC with respect to the results given by Pandit et al. (2007) and Brethee (2009)

\begin{tabular}{|c|c|c|c|c|c|c|}
\hline \multicolumn{7}{|c|}{ Mode } \\
\hline & 1 & 2 & 3 & 4 & 5 & 6 \\
\hline \multicolumn{7}{|l|}{ Cut-out size } \\
\hline $0.2 \mathrm{a}^{*} 0.2 \mathrm{a}$ (Present) & 9.827 & 25.833 & 26.277 & 40.301 & 54.818 & 63.052 \\
\hline Pandit et al. (2007) & 9.11 & 25.63 & 25.80 & 38.11 & 54.23 & 60.64 \\
\hline Brethee (2009) & 9.071 & 25.057 & 25.057 & 37.643 & 53.154 & 59.856 \\
\hline $0.4 \mathrm{a}^{*} 0.4 \mathrm{a}$ (Present) & 10.050 & 21.382 & 21.984 & 37.752 & 46.409 & 65.219 \\
\hline Pandit et al. (2007) & 9.12 & 20.25 & 20.34 & 35.67 & 44.76 & 61.81 \\
\hline Brethee (2009) & 9.061 & 19.930 & 19.930 & 35.070 & 42.866 & 60.270 \\
\hline $0.6 a^{*} 0.6 \mathrm{a}$ (Present) & 12.402 & 20.022 & 20.525 & 34.749 & 37.438 & 56.576 \\
\hline Pandit et al. (2007) & 11.31 & 18.69 & 18.71 & 32.81 & 34.34 & 53.11 \\
\hline Brethee (2009) & 11.085 & 18.173 & 18.173 & 31.560 & 33.920 & 51.712 \\
\hline $0.4 a^{*} 0.2 \mathrm{a}$ (Present) & 9.63 & 22.35 & 25.74 & 39.38 & 53.40 & 64.98 \\
\hline Pandit et al. (2007) & 8.85 & 21.31 & 27.82 & 39.12 & 51.22 & 62.14 \\
\hline Brethee (2009) & 8.76 & 20.57 & 54.35 & 36.57 & 50.83 & 60.81 \\
\hline $0.8 \mathrm{a}^{*} 0.4 \mathrm{a}$ (Present) & 10.83 & 13.21 & 30.58 & 34.90 & 55.77 & 66.97 \\
\hline Pandit et al. (2007) & 9.72 & 11.81 & 27.36 & 31.15 & 50.63 & 60.37 \\
\hline Brethee (2009) & 9.60 & 11.54 & 27.03 & 30.63 & 49.42 & 59.27 \\
\hline $0.6 \mathrm{a}^{*} 0.2 \mathrm{a}$ (Present) & 9.57 & 17.18 & 25.90 & 36.97 & 52.70 & 62.58 \\
\hline Pandit et al. (2007) & 8.54 & 15.87 & 25.45 & 34.87 & 51.26 & 60.13 \\
\hline Brethee (2009) & 8.49 & 15.27 & 25.08 & 34.02 & 50.24 & 59.21 \\
\hline
\end{tabular}

\subsection{Vibration of composite laminated plate with triangular cutout}

Table 2 shows the variation of first ten non-dimensional frequencies with size ratio $(d / b=0.2$, $0.3,0.4)$ of triangular cut-out for a cross-ply square laminate $\left(0^{0} / 90^{\circ} / 0^{\circ}\right)$ of aspect $\mathrm{ratio} \mathrm{a} / \mathrm{b}=1$ and 
thickness ratio $h / b=0.01$ for fully clamped boundary condition. The frequency for all mode decreases as the size ratio of cut-outs increases. Table 3 shows the variation of first ten non-dimensional frequencies with distance between cut-outs $(\mathrm{e} / \mathrm{b}=0.3,0.4,0.5)$ for a thin cross-ply square laminate $\left(0^{0} / 90^{0} / 0^{0}\right)$ of aspect ratio $\mathrm{a} / \mathrm{b}=1$, thickness ratio $\mathrm{h} / \mathrm{b}=0.01$, having triangular cut-out of size ratio $\mathrm{d} / \mathrm{b}=0.2$ at the center for fully clamped boundary condition. The frequency for first four modes decreases as the distance between cut-outs increases. Table 4 shows the variation of first ten nondimensional frequencies with different number of layers for a thin cross-ply square laminate $\left(0^{0} /\right.$ $\left.90^{0} / 0^{0} \ldots \ldots\right)$ of aspect ratio $\mathrm{a} / \mathrm{b}=1$ and thickness ratio $\mathrm{h} / \mathrm{b}=0.01$, having triangular cut-out of size ratio $\mathrm{d} / \mathrm{b}=0.2$ at the center for fully clamped boundary condition. The frequency in all ten modes increases as the number of layers increases. Table 5 shows the variation of first ten non-dimensional frequencies with different angles of lamina for an angle-ply square laminate $\left(\theta^{0} /-\theta^{0} / \theta^{0}\right)$ of aspect ratio $a / b=1$ and thickness ratio $h / b=0.01$, having triangular cut-out of size ratio $d / b=0.2$ at the center for fully clamped boundary condition. The frequency in all ten modes increases as the angle of lamina increases. Table 6 shows the variation of first ten non-dimensional frequencies with different boundary conditions (SSSS, SCSC and CCCC) for a thin cross-ply square laminate $\left(0^{0} / 90^{0} / 0^{0}\right)$ of aspect ratio $a / b=1$ and thickness ratio $h / b=0.01$, having triangular cut-out of size ratio $d / b=0.2$ at the center. The higher constraints at the edges results in higher frequencies.

Table 2. Variation of first ten natural frequency parameters $\left(\bar{\omega}=\frac{\omega b^{2}}{h} \sqrt{\frac{\rho}{E_{22}}}\right)$ with different values of size of cutout $(\mathrm{d} / \mathrm{b}=0.2,0.3,0.4)$ for a cross-ply laminate $\left(0^{0} / 90^{\circ} / 0^{0}\right)$ having triangular cut-out at the centre, $\left(K_{S}=5 / 6, \mathrm{a} / \mathrm{b}=1, \mathrm{~h} / \mathrm{b}=0.01\right)$ for fully clamped boundary condition

\begin{tabular}{lllllllllll}
\hline & \multicolumn{10}{c}{ Mode } \\
\cline { 2 - 10 } $\mathrm{d} / \mathrm{b}$ & 1 & 2 & 3 & 4 & 5 & 6 & 7 & 8 & 9 & 10 \\
\hline 0.2 & 26.127 & 53.175 & 56.265 & 84.937 & 92.959 & 102.664 & 111.871 & 121.441 & 133.985 & 144.825 \\
0.3 & 25.845 & 41.467 & 44.886 & 72.680 & 78.730 & 94.092 & 98.782 & 112.965 & 131.683 & 139.632 \\
0.4 & 25.542 & 39.402 & 40.584 & 66.684 & 68.466 & 92.413 & 102.781 & 106.967 & 120.667 & 139.085 \\
\hline
\end{tabular}

Table 3. Variation of first ten natural frequency parameters $\left(\bar{\omega}=\frac{\omega b^{2}}{h} \sqrt{\frac{\rho}{E_{22}}}\right)$ with different values of distance between cutouts $(\mathrm{e} / \mathrm{b}=0.3,0.4,0.5)$ for a cross-ply laminate $\left(0^{0} / 90^{0} / 0^{0}\right)$ having triangular cut-out at the center, $\left(K_{s}=5 / 6, \mathrm{a} / \mathrm{b}=1,1 / \mathrm{b}=\mathrm{d} / \mathrm{b}=0.2, \mathrm{~h} / \mathrm{b}=0.01\right)$ for fully clamped boundary condition

\begin{tabular}{lllllllllll}
\hline & \multicolumn{10}{c}{ Mode } \\
\cline { 2 - 11 } & 1 & 2 & 3 & 4 & 5 & 6 & 7 & 8 & 9 & 10 \\
$\mathrm{e} / \mathrm{b}$ & & & & & & & & & & \\
\hline 0.3 & 27.401 & 50.955 & 53.234 & 73.363 & 76.742 & 98.858 & 111.117 & 116.352 & 129.649 & 133.014 \\
0.4 & 26.734 & 44.743 & 51.141 & 71.898 & 83.400 & 93.864 & 106.668 & 119.438 & 122.36 & 133.851 \\
0.5 & 24.518 & 43.5673 & 48.889 & 67.650 & 80.144 & 90.491 & 104.985 & 114.370 & 122.876 & 163.287 \\
\hline
\end{tabular}

Table 4. Variation of first ten natural frequency parameters $\left(\bar{\omega}=\frac{\omega b^{2}}{h} \sqrt{\frac{\rho}{E_{22}}}\right)$ with different no. of layers $(\mathrm{n}=3,5,7,9)$ for a cross-ply laminate $\left(0^{0} / 90^{\circ} / 0^{0} \ldots \ldots \ldots\right)$ having triangular cutout at the center, $\left(K_{S}=5 / 6, \mathrm{a} / \mathrm{b}=1,1 / \mathrm{b}=\mathrm{d} / \mathrm{b}=0.2, \mathrm{~h} / \mathrm{b}=0.01\right)$ for fully clamped boundary condition

\begin{tabular}{|c|c|c|c|c|c|c|c|c|c|c|}
\hline \multirow[b]{2}{*}{$\begin{array}{l}\text { No. of } \\
\text { layers }\end{array}$} & \multicolumn{9}{|c|}{ Mode } & \multirow[b]{2}{*}{10} \\
\hline & 1 & 2 & 3 & 4 & 5 & 6 & 7 & 8 & 9 & \\
\hline 3 & 26.127 & 53.175 & 56.265 & 84.937 & 92.959 & 102.664 & 111.871 & 121.441 & 133.985 & 144.82 \\
\hline 5 & 30.448 & 62.985 & 64.627 & 94.018 & 106.04 & 113.791 & 130.485 & 136.287 & 153.539 & 164.61 \\
\hline 7 & 31.270 & 61.568 & 63.603 & 92.695 & 112.84 & 113.554 & 133.427 & 135.699 & 155.531 & 165.27 \\
\hline 9 & 31.516 & 64.844 & 65.914 & 95.713 & 109.52 & 116.155 & 136.786 & 140.221 & 160.177 & 170.89 \\
\hline
\end{tabular}


Table 5. Variation of first ten natural frequency parameters $\left(\bar{\omega}=\frac{\omega b^{2}}{h} \sqrt{\frac{\rho}{E_{22}}}\right)$ with different angle of layers $\left(\theta=15^{0}, 30^{0}, 45^{\circ}\right)$ for an angle-ply laminate $(\theta /-\theta / \theta)$ having triangular cutout at the center, $\left(K_{s}=5 / 6, \mathrm{a} / \mathrm{b}=1,1 / \mathrm{b}=\mathrm{d} / \mathrm{b}=0.2, \mathrm{~h} / \mathrm{b}=0.01\right)$ for fully clamped boundary condition

\begin{tabular}{|c|c|c|c|c|c|c|c|c|c|c|}
\hline \multirow[b]{2}{*}{$\theta$} & \multicolumn{9}{|c|}{ Mode } & \multirow[b]{2}{*}{10} \\
\hline & 1 & 2 & 3 & 4 & 5 & 6 & 7 & 8 & 9 & \\
\hline $15^{0}$ & 2.948 & 5.731 & 6.169 & 9.646 & 10.596 & 11.278 & 12.600 & 14.107 & 14.748 & 16.742 \\
\hline $30^{\circ}$ & 3.223 & 6.070 & 6.261 & 9.125 & 10.844 & 11.564 & 13.401 & 14.089 & 15.087 & 16.799 \\
\hline $45^{0}$ & 3.226 & 5.909 & 6.142 & 8.829 & 9.848 & 10.964 & 13.110 & 13.792 & 15.983 & 16.809 \\
\hline
\end{tabular}

Table 6. Variation of first ten natural frequency parameters $\left(\bar{\omega}=\frac{\omega b^{2}}{h} \sqrt{\frac{\rho}{E_{22}}}\right)$ with different boundary conditions (CCCC, SSSS, SCSC) for a cross-ply laminate $\left(0^{0} / 90^{\circ} / 0^{0}\right)$ having triangular cutout at the center, $\left(K_{S}=5 / 6, \mathrm{a} / \mathrm{b}=1, \mathrm{l} / \mathrm{b}=\mathrm{d} / \mathrm{b}=0.2, \mathrm{~h} / \mathrm{b}=0.01\right)$

\begin{tabular}{|c|c|c|c|c|c|c|c|c|c|c|}
\hline \multirow[b]{2}{*}{ B. C. } & \multicolumn{9}{|c|}{ Mode } & \multirow[b]{2}{*}{10} \\
\hline & 1 & 2 & 3 & 4 & 5 & 6 & 7 & 8 & 9 & \\
\hline SSSS & 9.453 & 29.385 & 33.903 & 48.274 & 58.379 & 66.761 & 76.921 & 78.191 & 97.493 & 103.416 \\
\hline SCSC & 20.401 & 39.579 & 49.978 & 66.773 & 68.092 & 86.765 & 93.509 & 96.967 & 111.396 & 135.492 \\
\hline CCCC & 26.127 & 53.175 & 56.265 & 84.937 & 92.959 & 102.664 & 111.871 & 121.441 & 133.985 & 144.825 \\
\hline
\end{tabular}

Fig. 4 shows the variation of first ten non-dimensional frequencies with aspect ratio $(\mathrm{a} / \mathrm{b}=1,1.5$, 2) for a cross-ply square laminate $\left(0^{0} / 90^{\circ} / 0^{0}\right)$ of thickness ratio $\mathrm{h} / \mathrm{b}=0.01$, having triangular cut-out of size ratio $\mathrm{d} / \mathrm{b}=0.2$ at the center for fully clamped boundary condition. The frequency in all modes decreases as the size of plate increases. Fig. 5 shows the variation of first ten non-dimensional frequencies with thickness ratio $(\mathrm{h} / \mathrm{b}=0.01,0.02,0.1,0.2)$ for a cross-ply square laminate $\left(0^{0} / 90^{0} /\right.$ $0^{0}$ ) of aspect ratio $a / b=1$, having triangular cut-out of size ratio $d / b=0.2$ at the center for fully clamped boundary condition. The frequency in all ten modes decreases as the thickness ratio increases. Fig. 6 shows the variation of first ten non-dimensional frequencies with different material properties $\left(\frac{E_{11}}{E_{22}}=10,20,30,40\right)$ for a thin cross-ply square laminate $\left(0^{0} / 90^{0} / 0^{0}\right)$ of aspect ratio $a / b=1$ and thickness ratio $h / b=0.01$, having triangular cut-out of size ratio $d / b=0.2$ at the center for fully clamped boundary condition. The frequency in all ten modes increases as the modulus ratio increases.

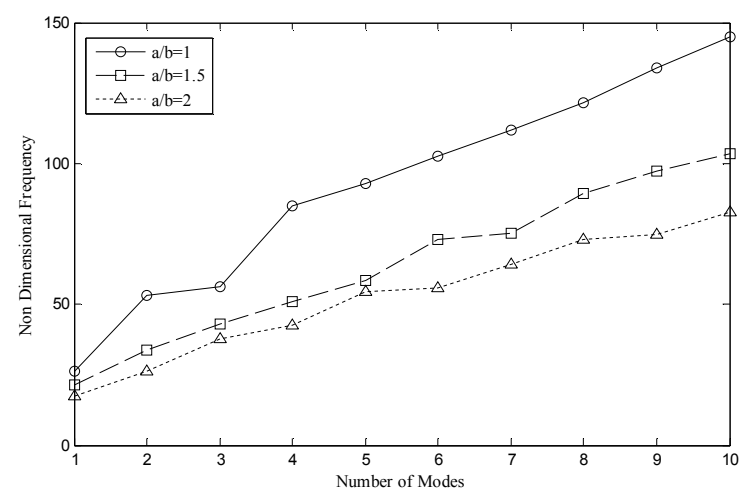

Fig. 4. Variation of first ten natural frequency parameters $\left(\bar{\omega}=\frac{\omega b^{2}}{h} \sqrt{\frac{\rho}{E_{22}}}\right)$ with size ratio $(\mathrm{a} / \mathrm{b}=1,1.5$, 2) for a cross-ply laminate $\left(0^{0} / 90^{0} / 0^{0}\right)$ having triangular cut-out at the center, $\left(K_{s}=5 / 6,1 / \mathrm{b}=\mathrm{d} / \mathrm{b}=0.2\right.$, $\mathrm{h} / \mathrm{b}=0.01$ ) for fully clamped boundary condition 


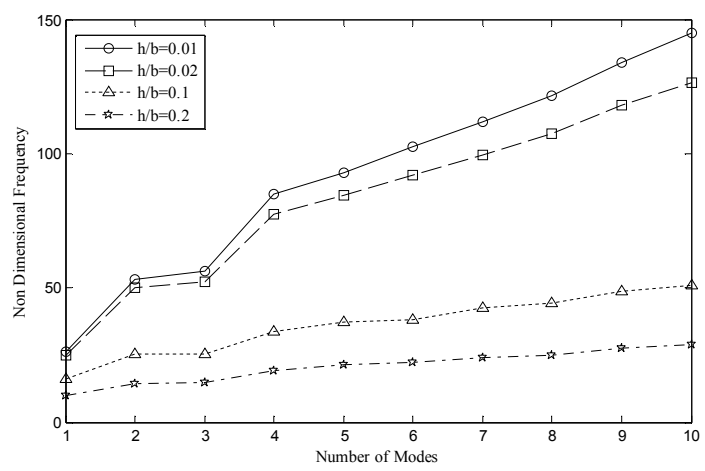

Fig. 5. Variation of first ten natural frequency parameters $\left(\bar{\omega}=\frac{\omega b^{2}}{h} \sqrt{\frac{\rho}{E_{22}}}\right)$ with thickness ratio $(\mathrm{h} / \mathrm{b}=0.01,0.02,0.1,0.2)$ for a cross-ply laminate $\left(0^{0} / 90^{\circ} / 0^{0}\right)$ having triangular cut-out at the centre, $\left(K_{s}=5 / 6, \mathrm{a} / \mathrm{b}=1,1 / \mathrm{b}=\mathrm{d} / \mathrm{b}=0.2\right)$ for fully clamped boundary condition

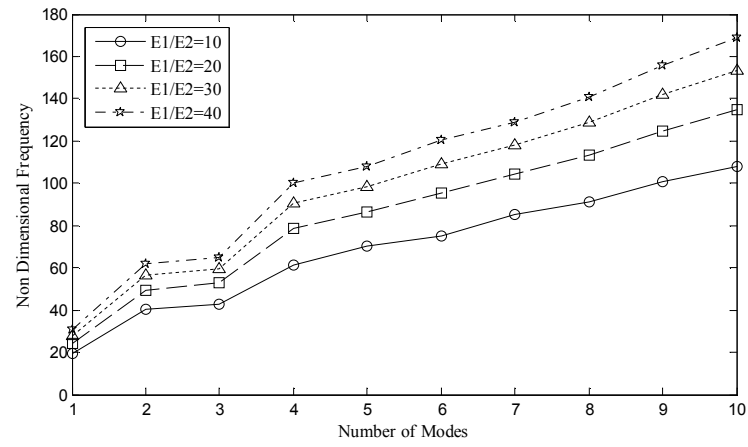

Fig. 6. Variation of first ten natural frequency parameters $\left(\bar{\omega}=\frac{\omega b^{2}}{h} \sqrt{\frac{\rho}{E_{22}}}\right)$ with different material properties $\left(\frac{E_{11}}{E_{22}}=10,20,30,40\right)$ for a cross-ply laminate $\left(0^{\circ} / 90^{\circ} / 0^{0}\right)$ having triangular cut-out at the centre, $\left(K_{s}=5 / 6, \mathrm{a} / \mathrm{b}=1,1 / \mathrm{b}=\mathrm{d} / \mathrm{b}=0.2, \mathrm{~h} / \mathrm{b}=0.01\right)$ for fully clamped boundary condition

\section{Conclusions}

In this paper, free vibration behavior of laminated composite plate with cutouts has been carried out using APDL code in ANSYS and validated with the available published results. A convergence and validation survey of the free vibration analysis of laminated composite plate has been obtained. It has been observed that the present model converged well with mesh refinement and the differences were within acceptable range. From the present parametric analysis following conclusions are made: The frequency increases with an increase in the number of layers, modulus ratio of plate and angle of lamina. The frequency decreases with an increase in aspect ratio, thickness ratio, size of cutout and distance between cutouts. The boundary conditions of the plate has played an important role in the free vibrations of the plate with cutouts. The Non-dimensional frequencies were higher for fully clamped boundary condition in comparison to other boundary conditions.

\section{References}

Aydogdu, M. \& Timarchi, T. (2003). Vibration analysis of cross-ply laminated square plates with general boundary conditions. Composite Science and Technology, 63 (7), 1061-1070.

Bathe, K. J. (1996). Finite element procedures. Prentie-Hall, Englewood cliffs. 
Boscolo, M. \& Banerjee, J. R. (2014). Layer-wise dynamic stiffness solution for free vibration analysis of laminated composite plates. Journal of Sound and Vibration, 333 (1), 200-227.

Brethee, K. F. (2009). Free vibration analysis of a symmetric and anti-symmetric laminated composite plate with a cutout at the center. Al-Qadisiya Journal for Engineering Sciences.

Chen, W. Q. \& Lue, C. F. (2005). 3D free vibration analysis of cross-ply laminated plates with one pair of opposite edges simply supported. Composite Structures, 69 (1), 77-87.

Civalek, O. (2008). Free vibration analysis of symmetrically laminated composite plates with first-order shear deformation theory (FSDT) by discrete singular convolution method. Finite Elements in Analysis and Design, 44 (12-13), 725-731.

Cui, X. Y., Liu, G. R. \& Li, G. Y. (2011). Bending and vibration responses of laminated composite plates using an edge-based smoothing technique. Engineering analysis with boundary elements, 35 (6), 818826.

Grover, N., Singh, B. N. \& Maiti, D. K. (2013). Analytical and finite element modeling of laminated composite and sandwich plates: An assessment of a new shear deformation theory for free vibration response. Internal Journal of Mechanical Sciences, 67, 89-99.

Karami, G., Malekzadeh, P. \& Mohebpour, S. R. (2006). DQM free vibration analysis of moderately thick symmetric laminated plates with elastically restrained edges. Composite Structures, 74 (1), 115-125.

Lahouel, Bahi-Eddine \& Guenfoud, Mohamed (2013). Comparative analysis of vibration between laminated composite plates with and without holes under compressive loads. World Academy of Science, Engineering and Technology, 7, 6-20.

Liew, K. M., Huang, Y. Q. \& Reddy, J. N. (2003). Vibration analysis of symmetrically laminated plates based on FSDT using the moving least squares differential quadrature method. Computer Methods in Applied Mechanics and Engineering, 192 (19), 2203-2222.

Luccioni, L. X. \& Dong, S. B. (1998). Levy-type finite element analysis of vibration and stability of thin and thick laminated composite rectangular plates. Composites Part B: Engineering, 29 (4), 459-475.

Marjanovic, M. \& Vuksanovic, D. (2014). Layerwise solution of free vibrations and buckling of laminated composite and sandwich plates with embedded delaminations. Journal of Composite Structures, 108, 9-20.

Ngo-Cong, D., Mai-Duy, N., Karunasena, W. \& Tran-Cong T. (2011). Free vibration analysis of laminated composite plates based on FSDT using one-dimensional IRBFN method. Computers and Structures, 89 (1-2), 1-13.

Pandit, M. K., Haldar, S., Mukhopadhyay, M. (2007). Free vibration analysis of laminated composite rectangular plate using finite element method. Journal of Reinforced Plastics and Composites, 26 (1), 69-80.

Sharma, A.K. \& Mittal, N.D. (2010). Review on stress and vibration analysis of composite plates. Journal of Applied Sciences, 10 (23), 3156-3166.

Sharma, A.K. \& Mittal, N.D., Sharma A. (2011). Free vibration analysis of moderately thick anti symmetric cross-ply laminated rectangular plates with elastic edge constraints. International Journal of Mechanical Sciences, 53, 688-695.

Sharma, A. K. \& Mittal, N. D. (2013). Free vibration analysis of laminated composite plates with elastically restrained edges using FEM. Central European Journal of Engineering. 3 (2), 306-315.

Sharma, A. K. \& Mittal, N.D. (2014). Free vibration analysis of moderately thick Anti-symmetric angleply laminated rectangular plates with elastic edge constraints. Mechanics of Advanced Materials and Structures, 21, 341-348.

Suresh Kumar, J., Dharma Raju, T. \& Vijaya Kumar Reddy, K. (2011). Vibration analysis of composite laminated plates using higher order shear deformation theory with zig-zag function. Indian Journal of Science and Technology, 4(8),960-966.

Xiang, S., Bi, Z. Y., Jiang, S. X., Jin, Y. X., \& Yang, M. S. (2011). Thin plate spline radial basis function for the free vibration analysis of laminated composite shells. Composite Structures, 93(2), 611-615.

Xiang, S., Shi, H., Wang, K. M., Ai, Y. T., \& Sha, Y. D. (2010). Thin plate spline radial basis functions for vibration analysis of clamped laminated composite plates. European Journal of MechanicsA/Solids, 29(5), 844-850.

Wilson, E. L., \& Itoh, T. (1983). An eigensolution strategy for large systems. Computers \& Structures, 16(1), 259-265. 